\title{
Medical device regulation in Europe - what is changing and how can I become more involved?
}

\author{
Robert A. Byrne*, $\mathrm{MB}, \mathrm{BCh}, \mathrm{PhD}$, Deputy Editor
}

The regulation of medical devices, particularly those that are implantable or high-risk, has received much attention in the lay media of late. Most recently, the release of analyses from a collaboration of international journalists in November 2018 made front-page news around the world. In many countries, authorities and physicians seemed to be caught on the wrong foot and put in a position of reaction rather than action. However, in Europe, reform of the medical device regulatory processes has been ongoing for a number of years. As cardiology devices are among the most frequent high-risk devices in clinical use, our community is affected more than other specialties. Indeed, among professional societies, the European Society of Cardiology has taken the lead in advocating for improved regulation for much of the last decade ${ }^{1,2}$.

Medical devices have been regulated in a coordinated fashion throughout Europe since the 1990s. At that time, the first Europewide medical device directives (MDD) were published in 1990 and $1993^{3,4}$. Over the past decade, a number of scandals emerged regarding patients harmed as a result of treatment with approved medical devices. These included the Poly Implant Prothèse (PIP) breast implant scandal, controversy with regard to metal on metal hip replacements, and complications after vaginal mesh implantation. Although the PIP breast implant scandal appeared to be more a case of fraud than a failure of approval processes, the notified body responsible for the conformity assessment of the product was found liable for damages due to failures in monitoring of the manufacturer ${ }^{5}$.
At the same time, the first steps were taken to overhaul device regulatory processes in Europe in the realisation that the MDD had become outdated. The overall goal of the initiative is to improve the clinical safety of medical devices on the market in Europe and to increase the credibility and reputation of the oversight system. These processes culminated in the publication of the new medical device regulation (MDR) in May 2017 ${ }^{6}$. In parallel, a separate regulation was published dealing with in vitro diagnostics. Regulations, unlike directives, immediately become law in all member states. Currently, we are in the middle of a transition period of three years, which permits devices to be evaluated under either MDD or MDR; this will come to an end in May 2020. After this time point, all medical devices must be approved according to MDR processes. Certificates of devices already on the market - known as legacy devices - will remain valid for a further four years until May 2024.

So what are the new features of the MDR and how can an individual cardiologist contribute to improved patient safety? Moreover, what are the new responsibilities for physicians and hospitals and what are the new opportunities for engagement? (Figure 1, Table 1)

\section{New features of the regulatory system}

Historically, devices in Europe are not approved but rather receive a conformity assessment by notified bodies, which, if passed, leads to a CE mark being issued. In conformity assessment, the 


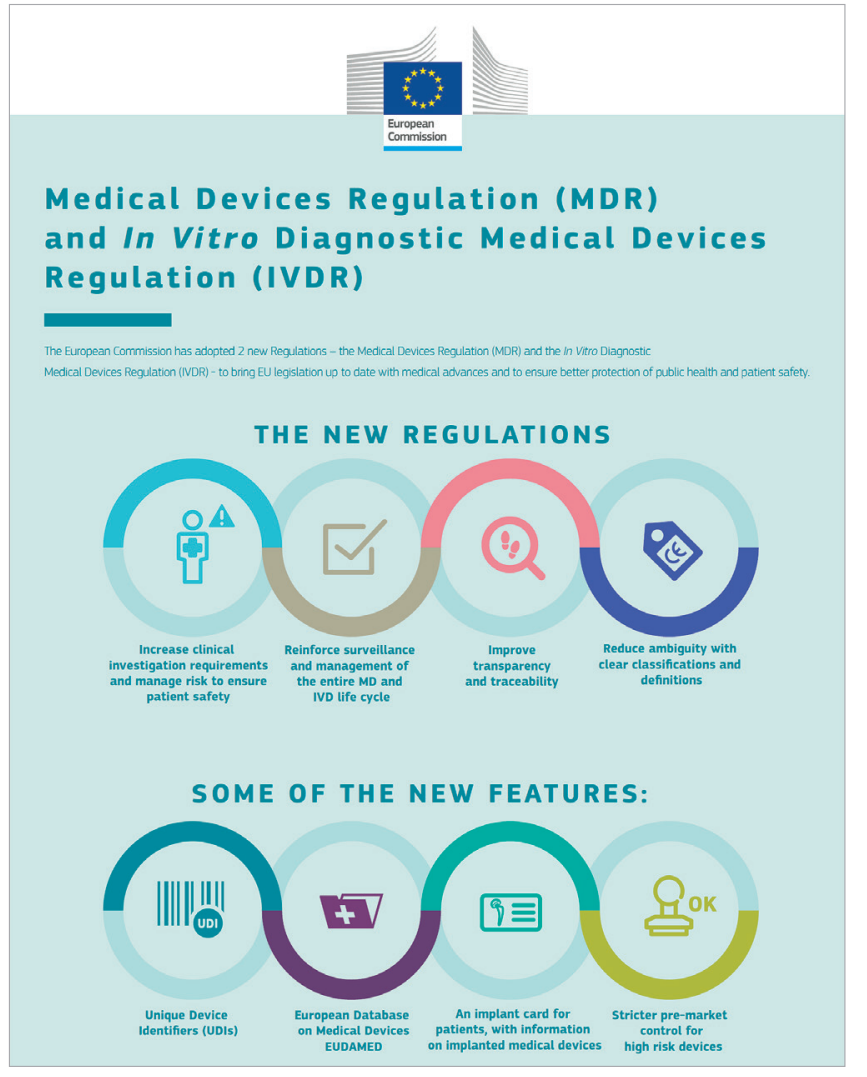

Figure 1. Key features of new regulations related to medical devices and in vitro diagnostics. Reproduced with permission of the European Commission.

bar to be reached has been "safety and performance as intended". This differs importantly from "safety and effectiveness", which has been the standard requirement in some other jurisdictions. Under MDR, the requirements for approval of high-risk devices in terms of clinical evidence will become greater. This is a development

\section{Table 1. Medical device regulation.}

\section{Improved device regulation - how can I be more involved?}

Be actively involved in vigilance, reporting adverse device incidents to both manufacturers and national regulatory agencies

Design and conduct or participate in post-marketing clinical registries

Ensure that processes are in place in your institution to capture and record Unique Device Identifier (UDI) data

Apply for membership of expert panels to advise on medical device evaluation

\section{Useful website links}

Full text of medical device regulation 2017/745 (in all EU languages): https://eur-lex.europa.eu/legal-content/EN/TXT/?uri=CELEX:020 17R0745-20170505

European Commission website on medical devices: https://ec.europa.eu/growth/sectors/medical-devices_en

Notification of upcoming call for European Commission expert panels on medical devices and in vitro diagnostic devices: https://ec.europa.eu/docsroom/documents/36041 that will be welcomed by most patients and physicians. The new MDR states that high-risk devices should show evidence of "clinical benefit", which seems to be an important raising of the bar. The type of clinical evidence that will be required for approval of devices will be defined by a regulators' implementation working group, which receives input from various stakeholders, including the ESC. At the same time, we as physicians are keen to see that our patients retain access to innovative devices as rapidly as possible, particularly in areas where a clear unmet need for devices exists. The impact of the changes in MDR on access to new devices will first become apparent in the years to come. While no separate breakthrough pathway is planned for innovative devices, it is envisaged that devices serving an unmet clinical need will continue to be available for patients in a timely manner.

The requirements, if a manufacturer wants to seek approval of a new medical device by virtue of demonstrating equivalency to a device already on the market, are being strengthened. This will make it less easy for "me too" devices to gain approval on the back of data from other devices. However, it should not mitigate against breakthrough devices. In addition, the submission of data gathered from compassionate use programmes will be made more difficult. In certain cases, this has been perceived to have been used as a back door to to obtaining evaluation by a notified body, circumventing more stringent clinical investigations.

A second important development relates to improving transparency ${ }^{7}$. In the past, it was difficult to gain access to the information that led a notified body to issue a certificate of conformity for a device. Under the MDR, the manufacturer must publish a summary of safety and clinical performance (SSCP) for highrisk devices and keep this updated on an annual basis. SSCP documents will be available on the European Union database of medical devices (EUDAMED). This database, which previously had been accessible only to regulators, will now be accessible publicly and is a critical element of the new system. The implementation work on EUDAMED, however, is progressing slowly, and it is unclear whether the public clinical interface will be ready for May 2020.

Thirdly, in terms of accountability, each medical device must be identifiable through a unique device identifier (UDI) system. Hospitals must ensure that processes are in place to record the UDI of each device used, in order to facilitate rapid identification of affected patients in case of problems that are identified post marketing. In addition, all patients must be issued with device passes, detailing the devices that they received. In many countries, these changes have already been implemented in full.

Fourthly, post-market surveillance requirements will be increased. This recognises that the medical device product lifecycle is not complete at the time of approval or conformity assessment. Under MDR, manufacturers have increased responsibility to collect post-marketing clinical follow-up data and publish any findings in a periodic safety update report. In parallel, robust vigilance procedures should be in place to enable collection and adjudication of adverse device events in clinical practice. In relation to both of these processes, physicians in general, and cardiologists 
in particular, have a critical role. We must ensure, as a community, that adverse device events with high-risk devices are reported to both manufacturers and regulatory agencies. Even incidents which seem relatively minor may have increased importance when aggregated with other reports. In addition, physicians have an important duty to design and conduct, or participate in clinical registries. Such registries are capable of identifying important adverse safety signals, as was the case with bioresorbable scaffolds. While early randomised clinical trials failed to detect a signal of adverse safety $^{8}$, a number of investigator-initiated registries highlighted the issue of scaffold thrombosis ${ }^{9,10}$, which was subsequently confirmed in larger-scale clinical trials ${ }^{1}$. While the MDR is clear in laying the responsibility for post-market surveillance at the feet of the manufacturers, as physicians we must appreciate the potentially important role of industry independent data capture and analysis ${ }^{12}$.

\section{Opportunities for engagement}

As discussed already, physicians have a central role to play in post-market surveillance, through participation in vigilance and in post-market clinical registries. In addition, physicians will also contribute to pre-market evaluation in certain circumstances. This may be through participation in clinical trials designed to generate data for device approval. Alternatively, it may take the form of participation in so-called expert panels, which will be introduced shortly under MDR. These new panels will review dossiers of documents produced by notified bodies for the evaluation of particular high-risk devices (known as clinical evaluation assessment reports), and decide whether additional investigation is necessary or not. The European Commission will publish a call later this year for experts willing to provide advice on expert panels. The burden of work is not inconsiderable and may be up to two days per month; reimbursement by the Commission is foreseen. The criteria for involvement as an expert will be published with the call and will include requirements related to clinical experience and potential conflicts of interest resolution.

The new MDR represents an important landmark in the regulation of medical devices in Europe. Many of the new features promise to deliver improved safety for patients treated with highrisk or implantable devices. On the other hand, concern exists regarding how the regulation will be implemented, with particular key infrastructure projects, such as the EUDAMED database, still to be delivered upon. What is sure is that there will be an increasing role for physician engagement. Although all medical specialties will be affected to some degree or another, cardiology is likely to be most fully impacted, particularly interventional cardiology. For this reason, we have a duty to be well informed about the changes that are taking place and to engage as much as possible with the new regulation.

\section{References}

1. Fraser AG, Daubert JC, Van de Werf F, Estes NA 3rd, Smith SC Jr, Krucoff MW, Vardas PE, Komajda M; participants. Clinical evaluation of cardiovascular devices: principles, problems, and proposals for European regulatory reform. Report of a policy conference of the European Society of Cardiology. Eur Heart J. 2011;32:1673-86

2. Fraser AG. Clinical evaluation of medical devices: light at the end of the tunnel? Eur Heart J. 2015;36:64-6.

3. Council Directive of 20 June 1990 on the approximation of the laws of the Member States relating to active implantable medical devices (90/385/EEC). https://eur-lex.europa.eu/legal-content/EN/TXT/PDF/?uri=CELEX:01990L 0385-20071011\&from=EN.

4. Council Directive 93/42/EEC of 14 June 1993 concerning medical devices. http://eur-lex.europa.eu/LexUriServ/LexUriServ.do?uri=CONSLEG:1993L00 42:20071011:en:PDF.

5. BBC News. PIP implant scandal: German firm ordered to pay damages. https://www.bbc.com/news/world-europe-24936958.

6. European Union. Regulation (EU) 2017/745 of the European Parliament and of the Council of 5 April 2017 on medical devices, amending Directive 2001/83/EC, Regulation (EC) No 178/2002 and Regulation (EC) No 1223/2009 and repealing Council Directives 90/385/EEC and 93/42/EEC. https://eur-lex. europa.eu/legal-content/EN/TXT/?uri=CELEX:02017R0745-20170505.

7. Fraser AG, Butchart EG, Szymanski P, Caiani EG, Crosby S, Kearney P, Van de Werf F. The need for transparency of clinical evidence for medical devices in Europe. Lancet. 2018;392:521-30.

8. Serruys PW, Chevalier B, Dudek D, Cequier A, Carrié D, Iniguez A, Dominici M, van der Schaaf RJ, Haude M, Wasungu L, Veldhof S, Peng L, Staehr P, Grundeken MJ, Ishibashi Y, Garcia-Garcia HM, Onuma Y. A bioresorbable everolimus-eluting scaffold versus a metallic everolimus-eluting stent for ischaemic heart disease caused by de-novo native coronary artery lesions (ABSORB II): an interim 1-year analysis of clinical and procedural secondary outcomes from a randomised controlled trial. Lancet. 2015;385: $43-54$.

9. Hoppmann P, Kufner S, Cassese S, Wiebe J, Schneider S, Pinieck S, Scheler L, Bernlochner I, Joner M, Schunkert H, Laugwitz KL, Kastrati A, Byrne RA. Angiographic and clinical outcomes of patients treated with everolimus-eluting bioresorbable stents in routine clinical practice: Results of the ISAR-ABSORB registry. Catheter Cardiovasc Interv. 2016;87:822-9.

10. Capodanno D, Gori T, Nef H, Latib A, Mehilli J, Lesiak M, Caramanno G, Naber C, Di Mario C, Colombo A, Capranzano P, Wiebe J, Araszkiewicz A, Geraci S, Pyxaras S, Mattesini A, Naganuma T, Munzel T, Tamburino C. Percutaneous coronary intervention with everolimus-eluting bioresorbable vascular scaffolds in routine clinical practice: early and midterm outcomes from the European multicentre GHOST-EU registry. EuroIntervention. 2015;10: $1144-53$.

11. Cassese S, Byrne RA, Jüni P, Wykrzykowska JJ, Puricel S, Ndrepepa G, Schunkert H, Fusaro M, Cook S, Kimura T, Henriques JPS, Serruys PW, Windecker S, Kastrati A. Midterm clinical outcomes with everolimus-eluting bioresorbable scaffolds versus everolimus-eluting metallic stents for percutaneous coronary interventions: a meta-analysis of randomised trials. EuroIntervention. 2018;13:1565-73.

12. Wallentin L, Gale CP, Maggioni A, Bardinet I, Casadei B. EuroHeart: European Unified Registries On Heart Care Evaluation and Randomized Trials: An ESC project to develop a new IT registry system which will encompass multiple features of cardiovascular medicine. Eur Heart J. 2019;40:2745-9. 